\title{
Recyclable Shape-memory and Mechanical Strength of Poly(lactic acid) Compounds Cross-linked by Thermo-reversible Diels-Alder Reaction
}

\author{
By Midori YAMASHIRO*, Kazuhiko INOUE, and Masatoshi IJI
}

We developed poly(lactic acid) (PLA) compounds which achieved recyclable shape-memory and practical strength. The PLA compounds were composed of a furan-modified poly(lactic acid) and a maleimide linker, and cross-linked by the Diels-Alder cyclo-addition between furan and maleimide functions. The cross-linking condition was optimized to increase a reaction ratio between furan and maleimide functions, and the increase in the reaction ratio decreased the defects in its structure and enhanced its strength. Furthermore, using a maleimide linker with a flexible unit (dodecamethylene dimaleimide) induced relaxation of the inner strain in the PLA compound also enhanced its strength.

KEY WORDS: Poly(lactic acid) / Shape-memory / Thermo-reversible Cross-linking / Diels-Alder Reaction / Recycling /

Biomass-based polymers made from renewable plant resources, including poly(lactic acid) (PLA), have recently received increasing attention as new environmentally friendly polymers and are now starting to be used in products. However, the applications of biomass-based polymers have been limited because many practical characteristics of biomass-based polymers are lower than those of conventional petroleumbased polymers. ${ }^{1,2}$

For biomass-based polymers to be used in a larger variety of products, the characteristics of such polymers should be superior to those of petroleum-based polymers. Therefore, we developed new intelligent PLA compounds that perform recyclable shape-memory by cross-linking PLA based on thermo-reversible Diels-Alder cyclo-addition. ${ }^{3-5}$ Our PLA compounds have the potential to expand the use of biomassbased polymers in future high-performance products, for example, biomedical devices and wearable electronic equipments, the shapes of which users can reform easily.

Generally, shape-memory polymers have cross-linked structures, which can have either intermolecular bonding or covalent bonding to determine their permanent shapes. ${ }^{6,7}$ Shape-memory polymers cross-linked by intermolecular bonding, for example, entanglement networks, crystal domains, and hydrogen bonding can be remolded into other shapes by melting them at temperatures above their melting points, however their shape-memory performance is insufficient because of creep behavior due to weak intermolecular bonding. Shape-memory polymers cross-linked by covalent bonding cannot be melted due to covalently cross-linked structures and then they are hard to be recycled into other products, although these shape-memory polymers have sufficient shape-memory because their creep behavior is retarded by strong covalent bonding. Therefore, conventional shape-memory polymers hardly perform as recyclable shape-memory.
In our previous work, we achieved recyclable shapememory by using thermo-reversible bonding, which is based on a Diels-Alder reaction, to cross-link PLA as a biomassbased polymer. Some kinds of Diels-Alder reactions are well known as thermo-reversible reactions ${ }^{8-13}$ and they are suitable to be introduced into PLA because the reactions occur between hydrophobic functions, which hardly attack the weak ester bond of it. In particular, a combination of furan and maleimide functions is relevant, because the thermo-reversible reaction works below the decomposition temperature of PLA $\left(200^{\circ} \mathrm{C}\right)$.

We synthesized a thermo-reversibly cross-linked PLA (TCP) composed of a furan-modified PLA and a maleimide linker, and the TCP was cross-linked by the Diels-Alder cycloaddition between furan and maleimide functions under a heating condition. The TCP exhibited stable shape-memory due to the covalently cross-linked structure below bondassociation temperature $\left(100^{\circ} \mathrm{C}\right)$. Furthermore, the TCP was easily recycled and its shape-memory was erased because the cross-link was disconnected by the retro-Diels-Alder reaction above bond-dissociation temperature $\left(160^{\circ} \mathrm{C}\right)$.

However, this TCP was too brittle to be used in highperformance products. We assumed that the brittleness is caused by the low reaction ratio between furan and maleimide functions and by the inner strain generated by the bulky and rigid linking units between furan and maleimide functions.

In this work, to improve the TCP's mechanical strength, we have studied adequate reaction conditions for higher reaction ratios between furan and maleimide functions, and we have researched the structures of linkers with flexible units, which are hexamethylene dimaleimide (HDM) and dodecamethylene dimaleimide (DDM), to enable relaxation of the inner strain in the TCP. 


\section{Furan-modified PLA (FP)}<smiles>O=C(O)CCC(=O)OCc1ccco1</smiles>

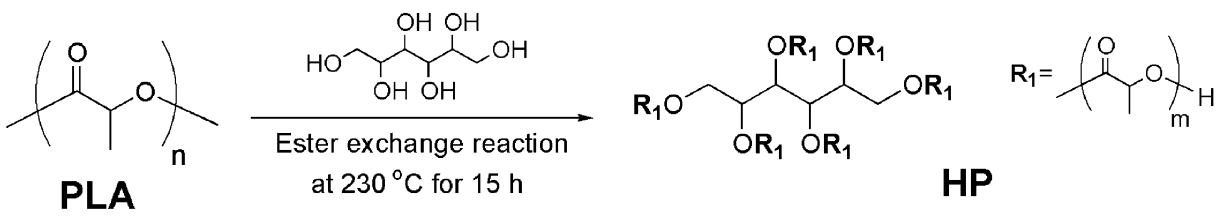<smiles>[R20]CC([R20])C([R20])C([R20])C([R20])C([R20])CO[R20]</smiles>

\section{Maleimide linkers (HDM, DDM, TMI)}

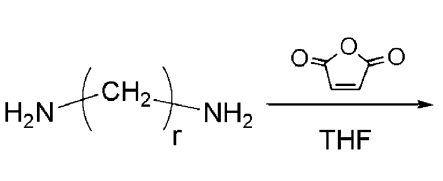<smiles>CC(C)(C)NC(=O)CC(C)(C)NC(=O)/C=C\C(=O)O</smiles>

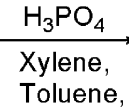

Dioxane

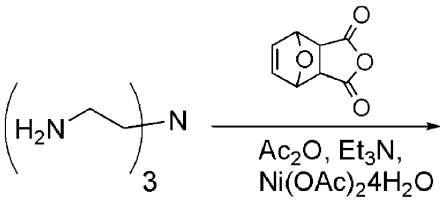<smiles></smiles>

TMI<smiles>CC(CCCCN1C(=O)C=CC1=O)C(C)(C)N1C(=O)C=CC1=O</smiles>

$\operatorname{HDM}(r=6)$

$\operatorname{DDM}(r=12)$

\section{Thermo-reversibly cross-linked PLA (TCP)}

\section{Diels-Alder cross-linking reaction \\ Condition I: $100^{\circ} \mathrm{C}$ for $1 \mathrm{~h}$ \\ FP + Maleimide linker \\ (HDM, DDM, TMI) \\ Condition II: $100^{\circ} \mathrm{C}$ for $1 \mathrm{~h}$ and $75^{\circ} \mathrm{C}$ for $20 \mathrm{~h}$ \\ retro-Diels-Alder reaction \\ Melted at $160^{\circ} \mathrm{C}$ for $10 \mathrm{~min}$}

Scheme 1. Synthesis of furan-modified PLA (FP), maleimide linkers (HDM, DDM, TMI), and thermo-reversibly cross-linked PLA (TCP).

\section{EXPERIMENTAL}

As shown in Scheme 1, a furan-modified PLA (FP), maleimide linkers (tris-(2-maleimidoethyl) amine (TMI), hexamethylene dimaleimide (HDM), and dodecamethylene dimaleimide (DDM)) were synthesized. The maleimide linkers were as previously described. ${ }^{3-5,14}$

\section{Materials}

PLA was purchased from Unitika Ltd., 1-Ethyl-3-(3-dimeth- ylaminopropyl) carbodiimide hydrochloride (WSC) was purchased from Wako Pure Chemical Industries, and other reagents were purchased from Kanto Chemical. All the reagents and solvents were used as received.

\section{Characterization}

NMR spectra were recorded at room temperature on a BRUKER AVANCE 400 operating at $400 \mathrm{MHz}$ for ${ }^{1} \mathrm{H}$ NMR and $100 \mathrm{MHz}$ for ${ }^{13} \mathrm{C} \mathrm{NMR}$ in $\mathrm{CDCl}_{3}$. Gel permeation chromatography (GPC) was carried out on a Shimadzu 10AVP. Calibration was based on polystyrene (PS) standards with 
narrow molecular weight distribution. The reaction ratio between furan and maleimide functions was determined using UV spectroscopy with a UV spectrophotometer (HITACHI U-2010). The three-point flexure test was performed using a universal testing machine (INSTRON 5567) with a crosshead speed of $1 \mathrm{~mm} / \mathrm{min}$ at room temperature. Thermal analysis was carried out using a differential scanning calorimeter (SEIKO Instruments DSC6200). The TCP was repeatedly heated from $-20^{\circ} \mathrm{C}$ to $180^{\circ} \mathrm{C}\left(10^{\circ} \mathrm{C} / \mathrm{min}\right)$ and quenched to $-20^{\circ} \mathrm{C}\left(50^{\circ} \mathrm{C} /\right.$ $\min$ ) in liquid nitrogen.

\section{Synthesis of Furan-modified PLA (FP)}

First, succinic acid mono-furan-2-ylmethyl ester (SFE) was synthesized. A chloroform solution including furfuryl alcohol $100 \mathrm{~g}$ (1.02 mol), succinic anhydride $112 \mathrm{~g}(1.12 \mathrm{~mol})$, and a catalytic amount of pyridine was refluxed for $15 \mathrm{~h}$ and then washed with aqueous hydrochloric acid. The organic layer was mixed with aqueous $\mathrm{NaOH}$. The water layer was separated, and acidified with aqueous hydrochloric acid until the $\mathrm{pH}$ reached 4. The acidified aqueous mixture was then extracted with chloroform. The organic layer was concentrated in vacuo to give SFE with a yield of $83 \% .{ }^{1} \mathrm{H} \mathrm{NMR}\left[\mathrm{CDCl}_{3}, \delta(\mathrm{ppm})\right]: 2.68$ (m, 4H, -OCOC $\left.\underline{\mathrm{H}}_{2} \underline{\mathrm{CH}}_{2}-\mathrm{COOH}\right), 5.09$ (s, 2H, furan- $\underline{\mathrm{C}}_{2}-\mathrm{O}-$ ), 6.36, $6.41(\mathrm{dd}, 2 \mathrm{H}, \mathrm{J}(\mathrm{Hz})=3.2,3.2,=\underline{\mathrm{HC}}-\mathrm{C} \underline{\mathrm{H}}=$ of furan $)$, $7.42(\mathrm{~s}, 1 \mathrm{H},-\mathrm{HC}=\mathrm{C} \underline{\mathrm{H}}-\mathrm{O}-$ of furan $),{ }^{13} \mathrm{C} \mathrm{NMR}\left[\mathrm{CDCl}_{3}\right.$, $\delta(\mathrm{ppm})]: 28.7,28.8 \quad\left(-\mathrm{OCO} \underline{C H}_{2} \underline{\mathrm{CH}}_{2}-\mathrm{COOH}\right), 58.4$ (furan$\left.\underline{\mathrm{CH}}_{2}-\mathrm{O}-\right), 111 \quad(-\mathrm{H} \underline{\mathrm{C}}=\underline{\mathrm{C}} \mathrm{H}-$ of furan $), 143 \quad(-\mathrm{HC}=\underline{\mathrm{CH}}-\mathrm{O}-$ of furan $), 149(-\mathrm{HC}=\mathrm{C}(\mathrm{C}) \mathrm{O}-$ of furan $), 172\left(-\mathrm{OCO}-\mathrm{CH}_{2} \mathrm{CH}_{2}-\right)$, $178\left(-\mathrm{CH}_{2} \mathrm{CH}_{2}-\underline{\mathrm{COOH}}\right)$.

Next, hydroxyl PLA (HP) was synthesized by an ester exchange reaction between D-solbitol $178 \mathrm{~g}(0.978 \mathrm{~mol})$ and PLA $2000 \mathrm{~g}\left(M_{\mathrm{n}}=76900,0.0260 \mathrm{~mol}\right)$ at $230{ }^{\circ} \mathrm{C}$ for $15 \mathrm{~h}$. The HP was purified by reprecipitation with chloroform and methanol. The molecular weight was measured by GPC and calculated by NMR data (GPC: $M_{\mathrm{n}}=4900, M_{\mathrm{w}} / M_{\mathrm{n}}=1.32$, NMR: $\left.M_{\mathrm{NMR}}=6280\right) .{ }^{1} \mathrm{H} \mathrm{NMR}\left[\mathrm{CDCl}_{3}, \delta(\mathrm{ppm})\right]: 1.56(\mathrm{~m}$, $244 \mathrm{H}, \mathrm{CH}_{3}$ of PLA), 4.10-4.50 (br, $\left.4 \mathrm{H},-\mathrm{CC}_{2}-\mathrm{O}-\mathrm{PLA}\right), 4.35$ $\left(\mathrm{q}, 6 \mathrm{H}, \overline{\mathrm{PLA}}-\mathrm{CH}\left(\mathrm{CH}_{3}\right) \mathrm{OH}\right), 5.18(\mathrm{~m}, 81.2 \mathrm{H}, \mathrm{CH}$ of PLA, -CC H-O-PLA). DSC: $T_{\mathrm{g}}=48.8^{\circ} \mathrm{C}, T_{m}=132{ }^{\circ} \mathrm{C}$.

Finally, the chloroform solution including SFE $20.4 \mathrm{~g}$ $(0.103 \mathrm{~mol})$, HP $100 \mathrm{~g}(0.0159 \mathrm{~mol})$, WSC $19.7 \mathrm{~g}(0.103 \mathrm{~mol})$, and pyridine $8.33 \mathrm{~mL}(0.103 \mathrm{~mol})$ was refluxed for $55 \mathrm{~h}$ and then washed with water. The polymeric product was reprecipitated by adding methanol and purified by silica gel in a mixture of chloroform and ethyl acetate. The filtrate was evaporated in vacuo to give furan-modified PLA (FP). The substitution degrees of furan groups were calculated with NMR data $(5.86$ eq. $/ \mathrm{mol})$. The molecular weight was measured by GPC and calculated by NMR data (GPC: $M_{\mathrm{n}}=6900$, $\left.M_{\mathrm{w}} / M_{\mathrm{n}}=1.27, \mathrm{NMR}: M_{\mathrm{NMR}}=7600\right) .{ }^{1} \mathrm{H} \mathrm{NMR}\left[\mathrm{CDCl}_{3}\right.$, $\delta(\mathrm{ppm})]: 1.54\left(\mathrm{~m}, 274 \mathrm{H}, \mathrm{CH}_{3}\right.$ of PLA), 2.60-2.80 (m, 23.4 $\mathrm{H}$, -OCO-C $\underline{\mathrm{H}}_{2} \mathrm{CH}_{2}-\mathrm{COO}-$ ), 4.10-4.50 (br, $4 \mathrm{H},-\mathrm{CCH}_{2}-\mathrm{O}-$ PLA), 4.35 (q, 0.14 H, PLA-C $\left.\underline{H}\left(\mathrm{CH}_{3}\right) \mathrm{OH}\right), 5.00-5.40(\mathrm{~m}$, 103.4 H, furan- $\underline{\mathrm{CH}}_{2}-\mathrm{O}-, \mathrm{CH}$ of PLA), 6.36, 6.40 (dd, $11.8 \mathrm{H}, \mathrm{J}$ $(\mathrm{Hz})=1.6,=\underline{\mathrm{HC}}-\mathrm{C} \underline{\mathrm{H}}=$ of furan $), 7.42(\mathrm{~s}, 5.86 \mathrm{H},-\mathrm{HC}=\mathrm{C} \underline{\mathrm{H}}-$ O- of furan). DSC: $T_{\mathrm{g}}=39.9^{\circ} \mathrm{C}, T_{m}=126^{\circ} \mathrm{C}$.

\section{Preparation of TCP test plates}

Test plates $(20 \times 35 \times 1.6 \mathrm{~mm})$ of TCP were obtained by hot-press molding the mixtures of FP and the maleimide linker in a mold heated at $160^{\circ} \mathrm{C}$ and heating them using the two reaction conditions listed in Table I.

\section{RESULTS AND DISCUSSION}

\section{Furan-modified PLA (FP) Preparation and Characteriza-} tion

Scheme 1 outlines the synthesis of FP. The FP was synthesized in $81 \%$ yield from a reaction of $\mathbf{H P}$ with SFE in the presence of WSC as a condensing agent, according to previously reported literature. ${ }^{3-5}{ }^{1} \mathrm{H}$ NMR and GPC data confirmed the structure of $\mathbf{F P}$.

Figure 1 illustrates the ${ }^{1} \mathrm{H}$ NMR spectra of PLA derivatives (HP and FP). The ${ }^{1} \mathrm{H}$ NMR spectrum of FP showed that, a decrease in a signal (e) related to the methylene moiety in $\mathbf{H P}$ (PLA-C $\left.\underline{\mathrm{H}}\left(\mathrm{CH}_{3}\right) \mathrm{OH}\right)$ at $4.35 \mathrm{ppm}$ and the appearance of new signals (1) related to the furan moiety at 6.36-6.40 and 7.42 ppm, suggesting that the furan group was successfully introduced in FP. By comparing the integral of the solbitol signal (f) (- $\left.\underline{\mathrm{CH}}_{2}-\mathrm{O}-\mathrm{PLA}\right)$ at $4.10-4.50 \mathrm{ppm}$ to that of the methylene moiety signal (m) $\left(\mathrm{PLA}-\mathrm{C} \underline{\mathrm{H}}\left(\mathrm{CH}_{3}\right) \mathrm{OH}\right)$ at $4.35 \mathrm{ppm}$, the substitution degrees of the furan group could be calculated $(5.86$ eq. $/ \mathrm{mol}$ ). Furthermore, the molecular weight of FP could be calculated by using the signal of furan and that of repeating unit of lactic acid. (FP: $\left.M_{\mathrm{NMR}}=7600\right)$.

The molecular weight of FP was also estimated by GPC using PS standards. The GPC traces of PLA derivatives are given in Figure 2. The difference of molecular weight between FP $\left(M_{\mathrm{n}}=6900\right)$ and HP $\left(M_{\mathrm{n}}=4900\right)$ was approximately 6 times that of SFE, and the molecular weight distributions of FP $\left(M_{\mathrm{w}} / M_{\mathrm{n}}=1.27\right)$ was similar to that of HP $\left(M_{\mathrm{w}} / M_{\mathrm{n}}=1.32\right)$. These data indicate that no significant chain degradation and cross-linking occurred during the condensation reaction for the synthesis of FP.

\section{Diels-Alder Reaction between FP and Maleimide Linker}

Thermo-reversibly cross-linked PLA (TCP) was obtained by mixing FP and a maleimide linker (with furan/maleimide $=1 / 1$ ) at $160^{\circ} \mathrm{C}$ and heating them under various reaction conditions. The UV spectroscopy confirmed the reaction ratio between furan and maleimide functions in the TCP. The films of TCPs were prepared by casting the melted TCP onto quartz substrates. UV absorption spectra showed a strong absorption maximum at $294 \mathrm{~nm}$, characteristic of the unreacted maleimide group. The reaction ratio was estimated by using molar absorptivity of the unreacted maleimide group in $\mathrm{CHCl}_{3}$.

\section{Mechanical Properties of TCPs}

Table I lists the mechanical properties of the TCPs that were cross-linked with different structural linkers under two reaction conditions. 

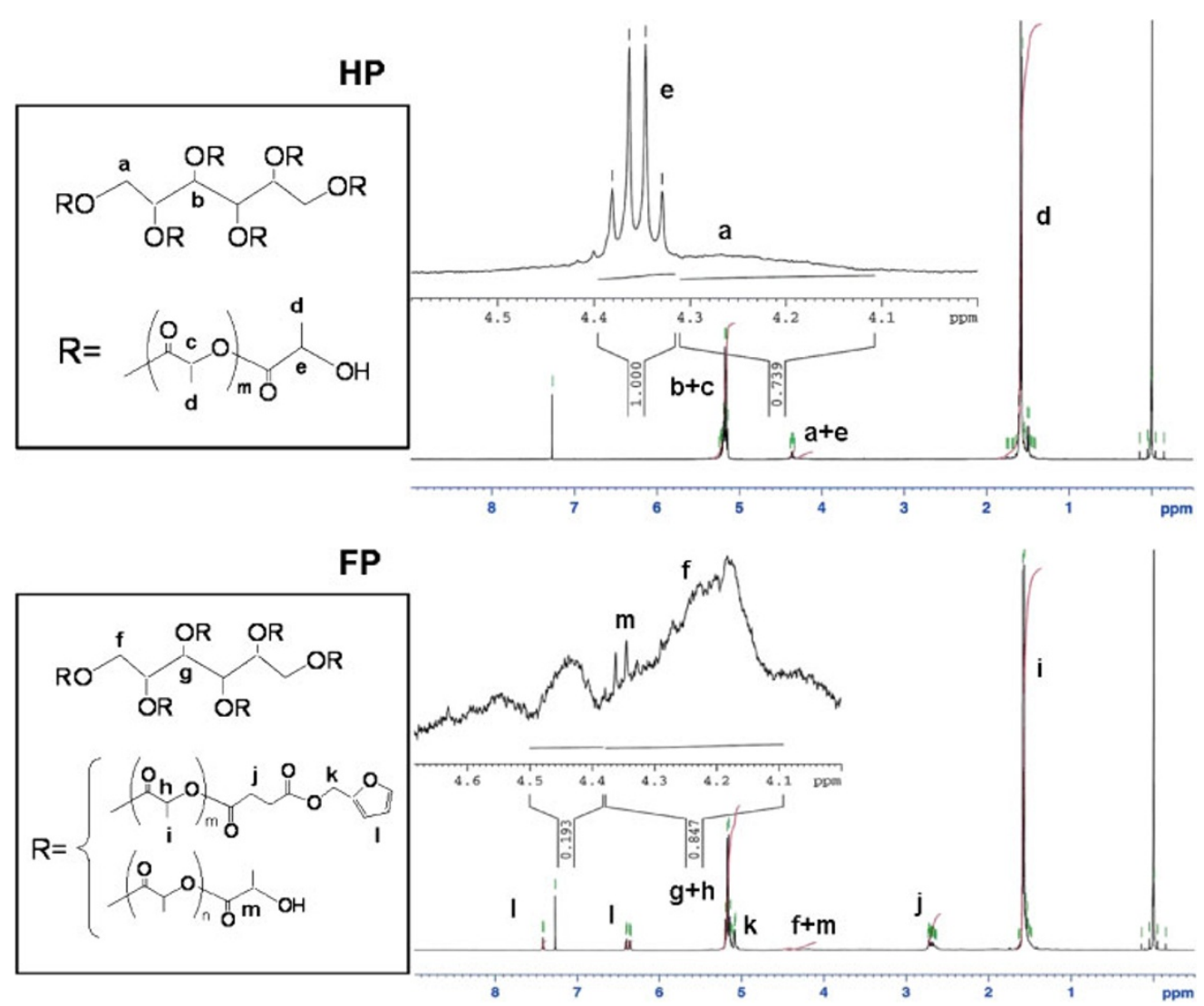

Figure 1. ${ }^{1} \mathrm{H}$ NMR spectra of PLA derivatives in $\mathrm{CDCl}_{3}$.

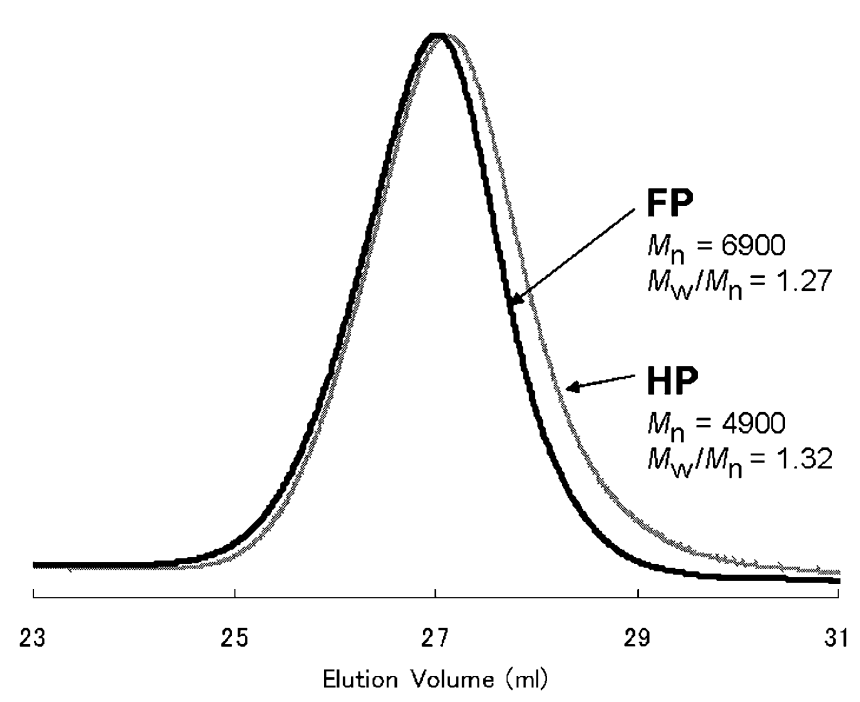

Figure 2. GPC profile of PLA derivatives.

First, we evaluated the influence of the reaction conditions on the strengths of the TCPs. For the first condition, the reaction temperature was set to $100^{\circ} \mathrm{C}$, hence the Diels-Alder reaction between furan and maleimide functions was monitored around $100{ }^{\circ} \mathrm{C}$ in our DSC study. ${ }^{3-5}$ In the case of the first condition (Condition I: $100{ }^{\circ} \mathrm{C}$ for $1 \mathrm{~h}$ ), which produced a low reaction ratio between furan and maleimide functions, the
Table I. Mechanical properties of TCPs

\begin{tabular}{ccccccc}
\hline Sample & Linker & $\begin{array}{c}\text { Reaction } \\
\text { condition }^{\mathrm{a}}\end{array}$ & $\begin{array}{c}\text { Flexural } \\
\text { strength } \\
(\mathrm{MPa})\end{array}$ & $\begin{array}{c}\text { Flexural } \\
\text { Modulus } \\
(\mathrm{GPa})\end{array}$ & $\begin{array}{c}\text { Reaction } \\
\text { ratio } \\
(\%)\end{array}$ & $\begin{array}{c}T_{\mathrm{g}} \\
\left({ }^{\circ} \mathrm{C}\right)\end{array}$ \\
\hline TCPd-I & DDM & I & 39.1 & 3.21 & 65.7 & 52.8 \\
TCPh-I & HDM & I & 19.2 & 2.30 & 66.0 & 51.5 \\
TCPt-I & TMI & I & 40.1 & 3.83 & 64.5 & 60.1 \\
\hdashline TCPd-II & DDM & II & $\underline{\mathbf{1 0 2}}$ & 3.50 & 77.6 & 55.7 \\
TCPh-II & HDM & II & 61.5 & 3.09 & 83.2 & 61.5 \\
TCPt-II & TMI & II & 61.7 & 3.93 & 77.5 & 66.1 \\
\hline
\end{tabular}

aCondition I: $100^{\circ} \mathrm{C}$ for $1 \mathrm{~h}$, condition II: $100^{\circ} \mathrm{C}$ for $1 \mathrm{~h}$ and $75^{\circ} \mathrm{C}$ for $20 \mathrm{~h}$. ${ }^{b}$ TCPx-y (x: initial of linker, $y$ : condition)

flexural strengths of the TCPs cross-linked with DDM (TCPdI), HDM (TCPh-I), and TMI (TCPt-I) were lower than that of neat PLA (120 MPa). We suggested that the insufficient flexural strengths were caused by defects in the cross-linked structures because of the low reaction ratios. Therefore, the condition to increase the reaction ratios of the TCPs was investigated.

Although the reaction time of Condition I was extended from 1 to $20 \mathrm{~h}$ at $100^{\circ} \mathrm{C}$, the reaction ratio did not increase. In contrast, the reaction ratio was greatly increased by heating the TCPs for $20 \mathrm{~h}$ at $75^{\circ} \mathrm{C}$ subsequent to Condition I (Condition II). The increase in the reaction ratio was mainly due to a decrease of the retro-Diels-Alder reaction by lowering the reaction temperature from $100^{\circ} \mathrm{C}$ to $75^{\circ} \mathrm{C}$. By changing the 


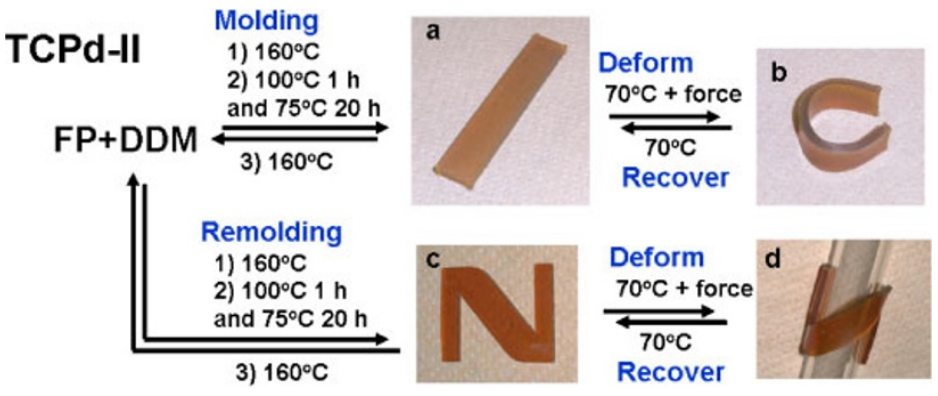

Figure 3. Recyclable shape-memory properties of TCPd-II. Molding and Remolding: 1) Melted in a mold, 2) Heated to react between furan and maleimide functions, 3) Disconnected the cross-linking through heating at $160^{\circ} \mathrm{C}$ and recovered FP and DDM.

condition from I to II, the strength of each TCP was greatly increased. This fact indicates that increasing the reaction ratio by changing the reaction condition effectively improves the strength of the TCPs. If the reaction temperature was lowered even further, the reaction ratio would increase. However it would take a long time because of decreasing molecular motion of the macromonomer at temperatures close to $T_{\mathrm{g}}$ of TCPs (around $60^{\circ} \mathrm{C}$ ).

Second, we evaluated the influence of the maleimide linkers on the strength of the TCPs. Under Condition II, the TCP cross-linked with DDM (TCPd-II) exhibited high strength (102 MPa) comparable to that of ABS resin ( $90 \mathrm{MPa}$ ), which is a petroleum-based polymer widely used in housings of electronic products, whereas the TCP crosslinked with HDM (TCPh-II) showed insufficient strength, as did the TCP with TMI (TCPt-II). The TCPs can increase inner strain at high reaction ratios, because their network structures are twisted by the cyclo-addition between furan and maleimide, which results in steric hindrance. Therefore, relaxing the inner strain by using DDM with a flexible dodecamethylene segment appears to be effective in improving the strength of the TCPd-II. However, HDM and TMI, which have shorter flexible units than DDM, were insufficient to relax the inner strain of the TCPs.

\section{Shape-memory and Recycle Behavior of TCP}

The recyclable shape-memory properties of TCPd-II are illustrated in Figure 3. It actually showed shape-memory behavior as good as that of a reference PLA cross-linked with rigid TMI. ${ }^{3-5}$ The original shape (a) was easily deformed into a C-shape (b) by heating the plate at $70^{\circ} \mathrm{C}$. The $\mathrm{C}$-shape was fixed by cooling it at room temperature. Then, the deformed C-shape (b) was restored to its original shape (a) by heating it at $70^{\circ} \mathrm{C}$ for $10 \mathrm{~s}$. This deformation and recovery were repeatedly practicable. Moreover, the plate were heated at $160{ }^{\circ} \mathrm{C}$ and remolded to a new shape of the letter $\mathrm{N}$ (c), and it behaved as a shape-memory polymer (c and d) again. This result shows that the memory of the original shape (a) of TCPd-II can be erased by disconnecting the cross-linking through heating at $160^{\circ} \mathrm{C}$. Thus, as shown here, TCPd-II has stable shape-memory and can be recycled. Other plates of the TCPs also exhibited recyclable shape-memory, just as TCPd-II did.

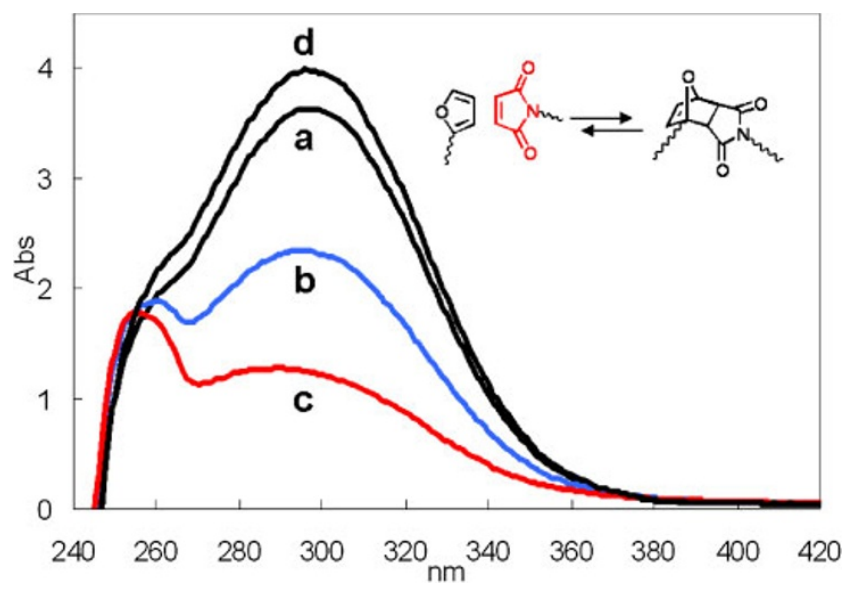

Figure 4. UV absorption spectra of TCPd-II. a: Melted at $160^{\circ} \mathrm{C}$, b: Cross linked under condition I $\left(100^{\circ} \mathrm{C} 1 \mathrm{~h}\right)$, c: Cross-linked under condition II $\left(100^{\circ} \mathrm{C} 1 \mathrm{~h}\right.$ and $\left.75^{\circ} \mathrm{C} 20 \mathrm{~h}\right)$ d: Recovered by heating at $160^{\circ} \mathrm{C}$.

The thermo-reversible reaction of the TCP was verified using UV spectroscopy. Figure 4 illustrates the UV spectra of TCPd-II. The absorption spectra showed the absorption maximum at $294 \mathrm{~nm}$, characteristic of the unreacted maleimide group. As the TCP was heated under $100^{\circ} \mathrm{C}$ for $1 \mathrm{~h}$, the absorption maximum decreased, furthermore, the absorption gradually decreased by heating it under $75^{\circ} \mathrm{C}$ for $20 \mathrm{~h}$. These results revealed that the Diels-Alder reaction progressed with the equilibrium shift to the coupling of the furan and maleimide by lowering the reaction temperature from 100 to $75^{\circ} \mathrm{C}$. Dissociated TCP, which was produced by rapid cooling after heating $\left(>160^{\circ} \mathrm{C}\right)$ showed strong absorption again. The intensity of absorption was almost the same as the intensity before cross-linking, suggesting that thermally-reversible cross-linking worked well in the TCPd-II.

Figure 5 presents the repeatedly thermo-reversible properties of TCPd-II using DSC. It is well known that the exothermal (at $100^{\circ} \mathrm{C}$ ) and endothermal peaks (at $160^{\circ} \mathrm{C}$ ) were assigned to association and dissociation respectively between furan and maleimide functions. Both of these peaks were observed repeatedly during heating following rapid cooling. This indicates that the furan and maleimide bonding reacts repeatedly in the TCP, just like a thermoswitch. 


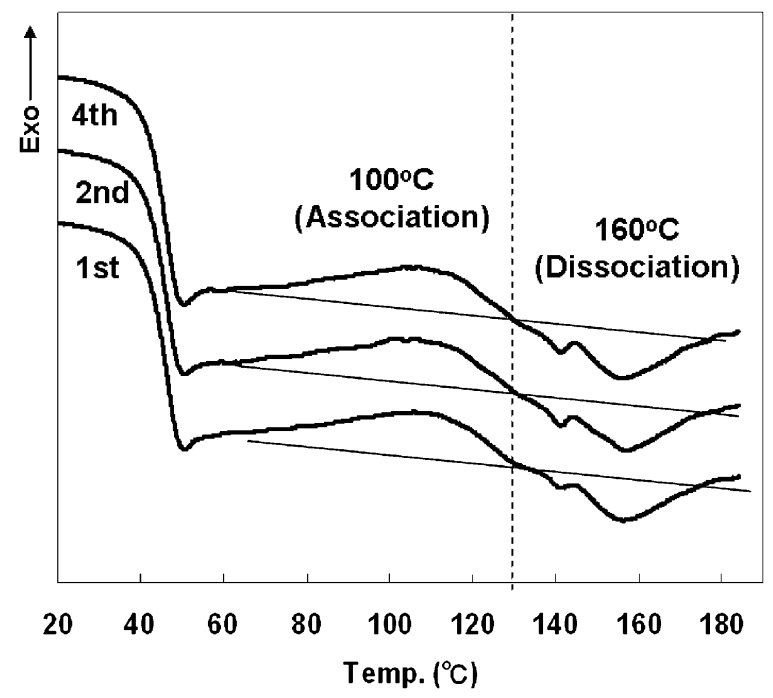

Figure 5. DSC thermograms of TCPd-II. Exothermal (at $100^{\circ} \mathrm{C}$ ) and endothermal peaks (at $160^{\circ} \mathrm{C}$ ) were assigned to association and dissociation respectively between furan and maleimide functions.

\section{CONCLUSION}

A recyclable shape-memory PLA compound has been developed by cross-linking PLA based on thermo-reversible Diels-Alder cyclo-addition between furan and maleimide functions. Furthermore its mechanical strength has been improved by increasing a reaction ratio between furan and maleimide functions, and by using a maleimide linker with a flexible unit. An adequate reaction condition $\left(100^{\circ} \mathrm{C}\right.$ for $1 \mathrm{~h}$ and $75^{\circ} \mathrm{C}$ for $20 \mathrm{~h}$ ) increased the reaction ratio between furan and maleimide functions, which decreased the defect in the structure of the thermo-reversibly cross-linked PLA (TCP) and then enhanced its strength. Using the flexible linker to decrease the inner strain of the TCP also enhanced its strength. The TCP exhibited excellent shape-memory owing to its cross-linked structure below the bond-association temperature $\left(100^{\circ} \mathrm{C}\right)$ and enables it to be recycled by melting it above the bonddissociation temperature $\left(160^{\circ} \mathrm{C}\right)$. The new shape-memory PLA will expand the application of biomass-based polymers to high performance products and will create new free-style products such as biomedical devices and wearable electronic equipments, the shapes of which users can reform easily.

Received: February 6, 2008

Accepted: April 14, 2008

Published: June 4, 2008

\section{REFERENCES}

1. D. Garlotta, J. Polym. Environ., 9, 63 (2001).

2. R. E. Drumright, P. R. Gruber, and D. E. Henton, Adv. Mater., 12, 1841 (2000).

3. K. Inoue, M. Yamashiro, and M. Iji, Presented at 230th ACS National Meeting, Washington, DC, August 28-September 1, 2005.

4. M. Shimura, K. Inoue, and M. Iji, U. S. Patent 0148465 A1 (2007).

5. K. Inoue, M. Yamashiro, and M. Iji, Kobunshi Ronbunshu, 62, 261 (2005).

6. A. Lendlein and S. Kelch, Angew. Chem., Int. Ed., 41, 2034 (2002).

7. K. Nakayama Nihon Gomи Kyoukaishi, 9, 529 (1990).

8. H. Kwart and K. King, Chem. Rev., 68, 415 (1968).

9. L. P. Engle and K. B. Wagener, J. Macromol. Sci. Rev. Macromol. Chem. Phys., C33, 239 (1993).

10. Y. Chujo, K. Sada, and T. Saegusa, Macromolecules, 23, 2636 (1990).

11. X. Chen, M. A. Dam, K. Ono, A. Mal, H. Shen, S. R. Nutt, K. Sheran, and F. Wudl, Science, 295, 1698 (2002).

12. R. Gheneim, C. Perez-Berumen, and A. Gandini, Macromolecules, 35, 7246 (2002).

13. M. Watanabe and N. Yoshie, Polymer, 47, 4946 (2006).

14. G. Kossmehl, H. I. Nagel, and A. Pahl, Angew. Makromol. Chem., 227, 139 (1995). 